\title{
Bismerthiazol Inhibits Xanthomonas citri subsp. citri Growth and Induces Differential Expression of Citrus Defense-Related Genes
}

\author{
Xiaoyue Yu, Cheryl M. Armstrong, Mingguo Zhou, and Yongping Duan
}

First and third authors: Nanjing Agriculture University, Nanjing 210095, China; and first, second, and fourth authors: U.S. Horticultural Research Laboratory, USDA-ARS, Fort Pierce, FL 34945. Accepted for publication 7 February 2016.

\begin{abstract}
Yu, X., Armstrong, C. M., Zhou, M., and Duan, Y. 2016. Bismerthiazol inhibits Xanthomonas citri subsp. citri growth and induces differential expression of citrus defense-related genes. Phytopathology 106:693-701.

Citrus canker, caused by Xanthomonas citri ssp. citri, is a serious disease that causes substantial economic losses to the citrus industry worldwide. The bactericide bismerthiazol has been used to control rice bacterial blight (X. oryzae pv. oryzae). In this paper, we demonstrate that bismerthiazol can effectively control citrus canker by both inhibiting the growth of $X$. citri ssp. citri and triggering the plant's host defense response through the expression of several pathogenesis-related genes $(P R 1, P R 2, C H I$, and $R p R d 1)$ and the

nonexpresser of PR genes (NPR1, NPR2, and NPR3) in 'Duncan' grapefruit, especially at early treatment times. In addition, we found that bismerthiazol induced the expression of the marker genes $\mathrm{CitCHS}$ and $\mathrm{CitCHI}$ in the flavonoid pathway and the PAL1 (phenylalanine ammonia lyase 1) gene in the salicylic acid (SA) biosynthesis pathway at different time points. Moreover, bismerthiazol also induced the expression of the priming defense-associated gene AZII. Taken together, these results indicate that the induction of the defense response in 'Duncan' grapefruit by bismerthiazol may involve the SA signaling pathway and the priming defense and that bismerthiazol may serve as an alternative to copper bactericides for the control of citrus canker.
\end{abstract}

Citrus canker, caused by Xanthomonas citri subsp. citri, is one of the most important and wide-spread bacterial diseases of citrus. It has caused extensive damage to commercial citrus cultivars in subtropical production areas of the world. In Florida, for example, an estimated \$12 million per year is spent to control it, yet it is still present and continues to spread (Pitino et al. 2015).

Citrus canker symptoms present as erumpent lesions on leaves, young stems, and fruits. The bacterium is easily dispersed by rain and can infect plants through stomata or wounds resulting from the feeding of insects. To reduce the inoculum level of citrus canker, current control measures include the use of copper-based sprays to protect the plants from infection and the eradication of infected trees (Gottwald et al. 2002). While the use of copper-based sprays allows trees to remain in production, there are many disadvantages associated with the long-term employment of copper bactericides. For example, although they are effective at reducing the bacterial population on the leaf surface, they do not have curative or systemic activity and must be applied multiple times throughout the year (Stall et al. 1981). Their effectiveness is also reduced by wind and rain and, with continual usage, the pathogen may grow resistant to copper sprays (Graham et al. 2004). In addition, accumulation of copper in soils can potentially become phytotoxic and have adverse environmental effects (Alva et al. 1995). In an effort to reduce the dependence on copper bactericides, alternative approaches to combat citrus canker are currently desired.

Utilization of host resistance is probably the most effective method to control plant diseases; however, a species of commercially grown

Corresponding authors: M. Zhou; E-mail address: mgzhou@njau.edu.cn; and Y. Duan; E-mail address: YongPing.Duan@ars.usda.gov

*The $\boldsymbol{e}$-Xtra logo stands for "electronic extra" and indicates that one supplementary table is published online.

http://dx.doi.org/10.1094/PHYTO-12-15-0328-R

This article is in the public domain and not copyrightable. It may be freely reprinted with customary crediting of the source. The American Phytopathological Society, 2016. citrus resistant to citrus canker has yet to be identified. Nevertheless, the induction of the plant's natural defense systems to ward off pathogen attack is a popular concept that warrants further investigation in citrus. Under constant biotic stress, plants have evolved an inducible defense response to protect themselves against potentially dangerous microbes such as fungi and bacteria (Harel et al. 2014; Horváth et al. 2007). This defense response is complex and is associated with many aspects, like the induction of defenseassociated gene expression, the reinforcement of the cell wall, and the activation of phytohormone signaling pathways (Bari and Jones 2009; van Loon et al. 2006). Two commonly known systemic resistance mechanisms are systemic acquired resistance (SAR) and induced systemic resistance (ISR). SAR is induced by pathogens or effectors and involves the accumulation of salicylic acid (SA), the induction of pathogenesis-related $(P R)$ gene expression, and the hypersensitive response (Durrant and Dong 2004). ISR is induced by colonization with nonpathogenic, plant growth-promoting rhizobacteria and fungi and is dependent upon the plant hormones ethylene and jasmonic acid (Conrath 2011). Many studies have reported that the induced resistance triggered by the external application of chemicals broadly affects plant metabolism (Friedrich et al. 1996; Lawton et al. 1996; Ryals et al. 1996). For example, both Arabidopsis and tobacco treated with benzothiazole (BTH) could activate SAR, which up-regulates defense response-related genes or SA accumulation and provides protection against a diverse set of pathogen challenges. In addition to these two broad-spectrum immunity systems, plants also have a physiological state called "priming," which allows cells to respond to extremely low levels of stimulus in a stronger and more rapid manner than nonprimed cells (Conrath 2011). Low doses of the plant defense activators BTH, $\beta$-aminobutyric acid (BABA), and thiamine are capable of priming susceptible hosts (Ahn et al. 2007; Conrath et al. 2002; Kohler et al. 2002).

Because the protection provided by SAR is often broad spectrum and can last for several weeks to several months (Ward et al. 1991), chemicals that can induce this response are of value in the field. 
Some of the known SAR-inducing chemicals include SA, isonicotinic acid, and acibenzolar- $S$-methyl, in addition to neonicotinoids and bismerthiazol, of which the latter two have been shown to control citrus canker (Francis et al. 2009; Graham and Myers 2011; Paranjape et al. 2014). Bismerthiazol is of particular interest because of its ability to act both as a protectant as well as a curative agent (Shen and Zhou 2001).

Bismerthiazol (N,N-methylene-bis [2-amino-5-mercapto-1, 3, 4thiadiazole]), which is also known as "Saikuzuo," "Yekuning," and "Yeqingshuang," was produced by the Sichuan Chemical Industry Design Academy in Sichuan, China, and is a derivative of the compound known as ATDA (2-amino-1,3,4-thiadiazole) (Zhongyin 1997). ATDA was originally developed in Japan to control bacterial blight of rice but its use was quickly forbidden because of its teratogenic effects (Beaudoin 1973). Modification of the chemical structure of ATDA into bismerthiazol reduced its toxicity level (the median lethal dose when given orally to rats $=4.640 \mathrm{mg} / \mathrm{kg}$ ), making it a safe alternative to ATDA. It has been in use in China for the control of bacterial blight of rice (caused by X. oryzae pv. oryzae), rice bacterial leaf streak (caused by $X$. oryzae pv. oryzicola), and citrus canker (caused by X. citri subsp. citri) since the 1970s, but understanding its mode of action is still in its infancy (Zhu et al. 2013). Recent studies on rice leaves infected by $X$. oryzae pv. oryzae have shown that bismerthiazol can activate SAR-related compounds, such as defense-related gene expression, callose deposition, enhancement of $\mathrm{H}_{2} \mathrm{O}_{2}$ production, and a hypersensitive response-like cell death (Liang et al. 2015b). Additional research demonstrated that the inhibitory effects of bismerthiazol on X. oryzae pv. oryzae can be seen in culture as well as in planta (Liang et al. 2015a). To date, no studies have been performed to define the effects of bismerthiazol on citrus canker. In this research, we chose a technical grade of bismerthiazol with a high purity (92.5\%) compared with the industrial bactericide, which is wettable powder with only $20 \%$ effective components (Sun et al. 2011), to evaluate the effectiveness of bismerthiazol against $X$. citri subsp. citri in culture and in planta. We show that the ability of bismerthiazol to cure citrus canker is related not only to its capacity to affect the growth of $X$. citri subsp. citri but also to upregulate various defense response-associated genes in grapefruit. This not only confirms the efficacy of bismerthiazol against $X$. citri subsp. citri but also advances our understanding of its mode of action against Xanthomonas species.

\section{MATERIALS AND METHODS}

Plant material. The citrus species used in this study was 'Duncan' grapefruit (Citrus paradise Macfadyen). All plants were grown under greenhouse conditions. All experiments were performed on new flushes.

Effects of bismerthiazol on the growth of $X$. citri subsp. citri in planta and in culture. $X$. citri subsp. citri (A strain 3213) (Pitino et al. 2015) was used in this study to determine the bactericidal effects of bismerthiazol. In-culture assays were conducted by culturing the bacteria in nutrient broth (NB) medium at $28^{\circ} \mathrm{C}$ until the optical density at $600 \mathrm{~nm}\left(\mathrm{OD}_{600}\right)$ reached 0.3 . Then, $20 \mu \mathrm{l}$ of the cell suspension was added to $2 \mathrm{ml}$ of NB medium to a final concentration of about $10^{6} \mathrm{CFU} / \mathrm{ml}$. To evaluate the minimum inhibitory concentration (MIC), growth of $X$. citri subsp. citri in NB medium containing various concentrations of bismerthiazol $(30,50,100,150$, and $160 \mu \mathrm{g} / \mathrm{ml})$ was measured as described below. For solubility purposes, the bismerthiazol (purity, 92.5\%; Longwan Agrichemical Co. Ltd.) was dissolved in pure $N, N$-dimethylformamide (DMF) (Sigma). According to a previous study, bacterial growth was not affected by a $1 \%$ (vol/vol) DMF solution (Wadhwani et al. 2009); thus, DMF was added to the various concentrations of bismerthiazol until the final concentration of DMF in the NB medium reached 1\% DMF. The control was cultured in a $1 \%$ DMF NB solution without the addition of bismerthiazol. All cultures were grown at $28^{\circ} \mathrm{C}$ and the $\mathrm{OD}_{600}$ was measured after $24 \mathrm{~h}$. The MIC was determined as the lowest concentration of bismerthiazol at which bacteria failed to grow. To evaluate the minimum bactericide concentration (MBC), $20 \mu \mathrm{l}$ of each suspension in which bacteria growth was not observed was plated in nutrient agar (NA) medium. The plates were incubated at $28^{\circ} \mathrm{C}$ for $24 \mathrm{~h}$. The $\mathrm{MBC}$ is the lowest concentration at which bacteria failed to grow in NB medium with bismerthiazol after subsequent transfer to NA plates (Bajpai et al. 2010). MIC and MBC evaluation experiments were performed three times.

For the in planta assays, inoculum was prepared by culturing $X$. citri subsp. citri in NB medium overnight. The $\mathrm{OD}_{600}$ of the bacterium was adjusted to 0.3 with sterile tap water containing $0.1 \%$ Silwet L-77. The suspension was then diluted 1:100 with sterile tap water to give an inoculation suspension containing approximately $10^{6} \mathrm{CFU} / \mathrm{ml}$ (McCollum et al. 2011). To determine the effective concentration of the bismerthiazol against X. citri subsp. citri, 'Duncan' grapefruit plants with new flushes were sprayed with bismerthiazol suspensions of $100,200,300$, and $400 \mu \mathrm{g} / \mathrm{ml}$ one day before inoculation with $X$. citri subsp. citri. To determine the optimum treatment time, 'Duncan' grapefruit plants with new flushes were sprayed with a bismerthiazol suspension of $400 \mu \mathrm{g} / \mathrm{ml}$ $5,3,1$ and day prior to inoculation and 1 and 3 days postinoculation. Samples were collected 14 days postinoculation from four leaves of each tree. A 7-mm-diameter disc of each leaf was removed with a No.4 cork borer. The four discs were weighed and DNA was extracted as previously described (Pitino et al. 2015). The total DNA was eluted in $100 \mu \mathrm{l}$ of nucleic acid free water and was used for quantitative polymerase chain reaction (qPCR) directly. The primers targeting the $p t h A$ gene, VM3 (5'-GCATTTGATGACGCCATGAC) and VM4 (5'-TCCCTGATGCCTGGAGGATA), were used for quantification of $X$. citri subsp. citri (Mavrodieva et al. 2004). Total DNA $(2 \mu \mathrm{l})$ was used as template for qPCR to determine the abundance of $p$ thA DNA. The qPCR conditions were $95^{\circ} \mathrm{C}$ for $2 \mathrm{~min}, 40$ cycles of $94^{\circ} \mathrm{C}$ for $45 \mathrm{~s}, 60^{\circ} \mathrm{C}$ for $45 \mathrm{~s}$, and $72^{\circ} \mathrm{C}$ for $45 \mathrm{~s}$, followed by a melt curve analysis sequence. The equation used to convert cyce threshold $(\mathrm{Ct})$ value to the copy number $(\mathrm{CN})$ of $p$ th $A$ gene was $\mathrm{CN}=$ $(38.3-\mathrm{Ct}) / 3.56$. The copy number of $p t h A$ gene per $X$. citri subsp. citri cell has been estimated to be 40 ; therefore, the number of $X$. citri subsp. citri cells is CN/40. The results were expressed as the number of cells per milligram of tissues (Stover and McCollum 2011). To determine the effect of bismerthiazol on the bacterium, we calculated the inhibition rate of each treatment compared with control samples. The equation used was: Inhibition rate $(\%)=($ cell number $_{(\text {control })}-$ cell number $\left._{(\text {treatment })}\right) /$ cell number $($ control) . All the experiments were performed more than three times.

Relative gene expression. Citrus containing new flush tissues were sprayed with $400 \mu \mathrm{g}$ of bismerthiazol per milliliter and young leaves were collected at 0 and $6 \mathrm{~h}$ and 1,3 , and 5 days posttreatment $(\mathrm{dpt})$. Three plants of each treatment were used as biological replicates. Total RNA was extracted using the Invitrogen RNA extraction kit according to the manufacturer's instructions. The RNA concentration and quality were detected with the Nano drop spectrophotometer (Thermo Scientific). The RNA was treated with DNA-free DNase (Promega). RNA $(1 \mu \mathrm{g})$ was used to synthesize cDNA via M-MLV reverse transcription (Promega) and an oligo (dT15) primer, according to the manufacturer's instructions. Gene expression was determined by real-time PCR using SYBR Green (Applied Biosystems). SYBR Green real-time PCR amplifications were performed in a Mastercycler ep realplex (Eppendorf). The real-time PCR conditions were $95^{\circ} \mathrm{C}$ for $30 \mathrm{~s}$, followed by 40 cycles of $95^{\circ} \mathrm{C}$ for $5 \mathrm{~s}, 55^{\circ} \mathrm{C}$ for $15 \mathrm{~s}$, and $70^{\circ} \mathrm{C}$ for $10 \mathrm{~s}$, followed by a melt curve analysis sequence. The GADPH gene was used as endogenous control. All the primers used for real-time PCR are shown in Supplementary Table S1. The $0-\mathrm{h}$ posttreatment (hpt) samples were used as the reference to calculate the relative expression ratio by $\Delta \Delta \mathrm{Ct}$ method. The upregulation was considered significant when the relative expression ratio was $\geq 2$-fold and downregulation was 
considered significant when the relative expression ratio was $\leq 0.5$-fold. All the experiments were performed at least twice and showed similar results.

\section{RESULTS}

Bismerthiazol inhibits the growth of $X$. citri subsp. citri in culture and in planta. Bismerthiazol is registered in China as an effective bactericide for controlling Xanthomonas pathogens such as $X$. oryzae pv. oryzae, $X$. oryzae pv. oryzicola, and $X$. citri subsp. citri. To confirm the effect of bismerthiazol on $X$. citri subsp. citri in culture, we measured the growth of $X$. citri subsp. citri in NB medium under various concentrations of bismerthiazol. The results showed that the inhibition rates were 11.66, 21.84, 64.13, 95.44 and $99.19 \%$ when cultured in NB medium with final concentrations of 30 , $50,100,150$, and $160 \mu \mathrm{g}$ of bismerthiazol per milliliter, respectively (Fig. 1A). The $\mathrm{OD}_{600}$ value was not detectable at concentrations of bismerthiazol $\geq 170 \mu \mathrm{g} / \mathrm{ml}$. We transferred cell suspensions treated with bismerthiazol at $0,200,250,300$, and $400 \mu \mathrm{g} / \mathrm{ml}$ onto agar plates and observed their growth at $24 \mathrm{~h}$. We failed to observe any colony formation on agar plates for suspensions treated with bismerthiazol at $\geq 300 \mu \mathrm{g} / \mathrm{ml}$. Thus, the MIC and MBC of bismerthiazole against $X$. citri subsp. citri were defined as 170 and $300 \mu \mathrm{g} / \mathrm{ml}$, respectively.

We used 'Duncan' grapefruit as a host plant to investigate the effect of bismerthiazol on citrus canker in planta. Using qPCR, X. citri subsp. citri-specific primers, the $X$. citri subsp. citri inhibition rates were quantified as $30.45,59.32,95.84$, and $96.10 \%$ when grapefruit plants were treated with bismerthiazol at $100,200,300$, and $400 \mu \mathrm{g} / \mathrm{ml}$, respectively, 1 day prior to inoculation (Fig. 1B). We also investigated if treatment time affected the effectiveness of bismerthiazol in eliminating $X$. citri subsp. citri in grapefruit. The $X$. citri subsp. citri inhibition rates were $91.65,94.40$, and $96.94 \%$ when grapefruit plants were treated with bismerthiazol at $400 \mu \mathrm{g} / \mathrm{ml}$ for 5,3 , and 1 day prior to inoculation, respectively (Fig. 1C). Grapefruit treated with bismerthiazol at $400 \mu \mathrm{g} / \mathrm{ml}$ at 1 and 3 days postinoculation showed an inhibition rate of 94.90 and $61.90 \%$, respectively.
Bismerthiazol induces $P R$ genes and nonexpresser of $P R$ $(N P R)$ gene expression in 'Duncan' grapefruit at early treatment times. Previously, it was shown that rice treated with bismerthiazol upregulated defense-related genes upon $X$. oryzae $\mathrm{pv}$. oryzae inoculation compared with noninoculated controls (Liang et al. 2015b). In order to investigate whether bismerthiazol could also induce the expression of defense-associated genes in healthy citrus, we sprayed a $400-\mu \mathrm{g} / \mathrm{ml}$ suspension of bismerthiazol on healthy grapefruit leaves and collected young leaf tissues at 0 and $6 \mathrm{~h}$ and 1,3 , and $5 \mathrm{dpt}$. We then studied the following four representative $P R$ genes, all of which have been reported to be induced by pathogen infection or chemical compounds: PRI (PR protein 1), a molecular marker for SAR that can be induced by BTH, thiamine, and SA (Ahn et al. 2007; Friedrich et al. 1996); PR2 ( $\beta-1$, 3 -glucanase) and $C H I$ (chitinases), which belong to the PR-2 and PR-3 families and are strongly induced when plants respond to wounding or infection by pathogens (Burketová et al. 1999; Dufour et al. 2013; Mauch et al. 1988); and RdRpl (RNA-dependent RNA polymerase 1), which synthesizes short cRNAs, using cellular or viral RNAs as templates, and is inducible upon SA treatment of plants (Xie et al. 2001). The results showed that the level of $P R 2$ gene expression increased sevenfold at $6 \mathrm{~h}$ and $1 \mathrm{dpt}$, while $\mathrm{CHI}$ expression increased ninefold at $6 \mathrm{~h}$ and 2.5 -fold at $1 \mathrm{dpt}$ (Fig. 2B and C). Although the expression level increased for PRl and RdRpl, the increase was not as dramatic as the other two genes, reaching about fourfold during the first day after treatment (Fig. 2A and D). As a control, it was noted that the expression level of these genes remained essentially unchanged across the same time points in plants treated with water.

Expression of the $P R$ genes is dependent on the activation of $N P R$ genes after SAR induction (Cao et al. 1994; Dong 2004). To identify if bismerthiazol is involved in the regulation of $N P R$ genes, we measured the expression level of NPR1, NPR2, and NPR3 (homologous to Arabidopsis NPR1,NPR3, and NPR4) in 'Duncan' grapefruit plants. The data showed that expression of NPRI and $N P R 2$ is up-regulated approximately fourfold at $6 \mathrm{~h}$ but is restored to
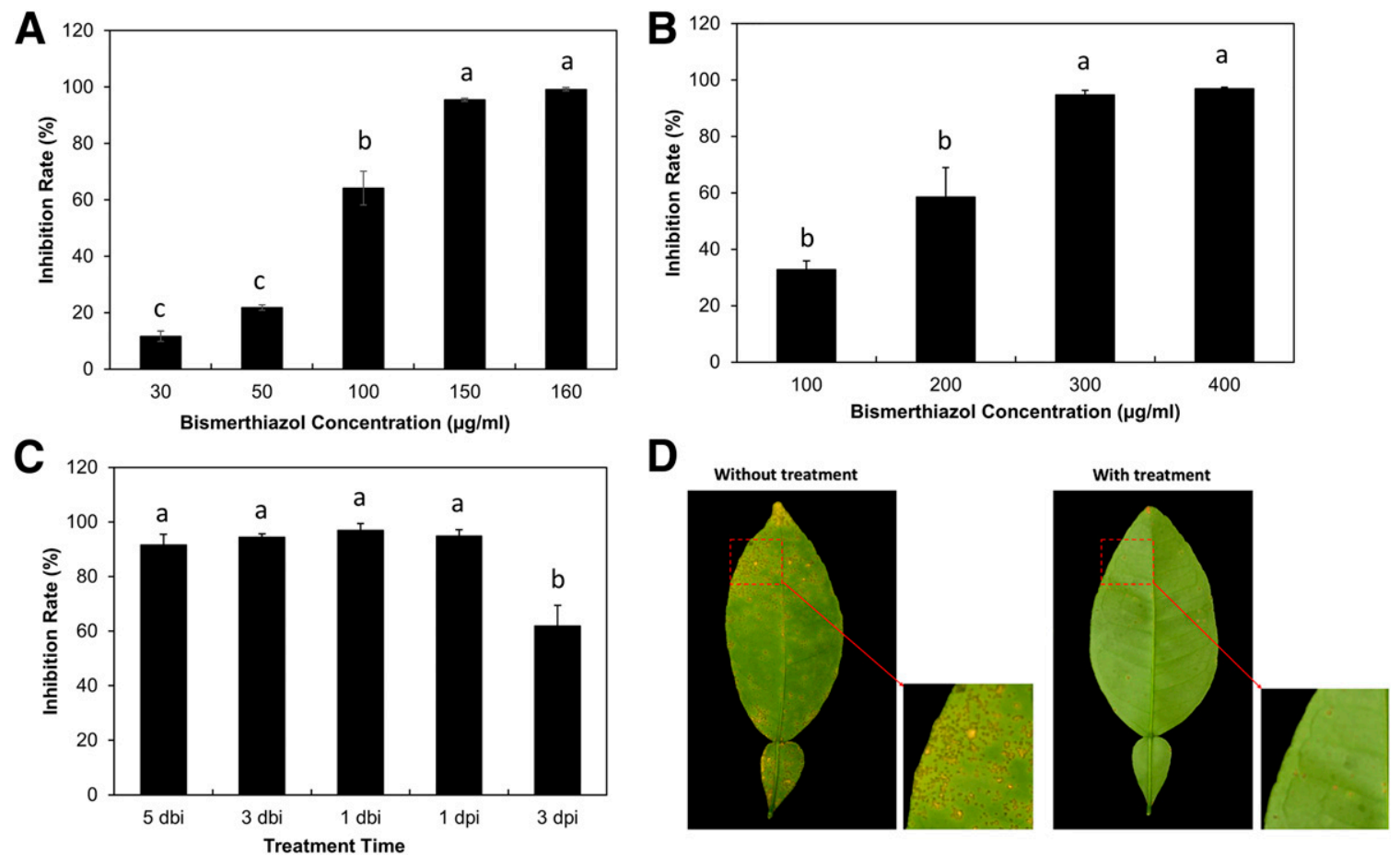

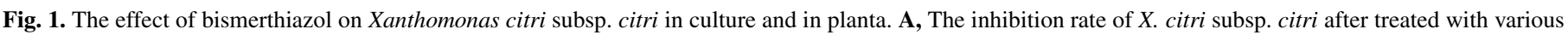

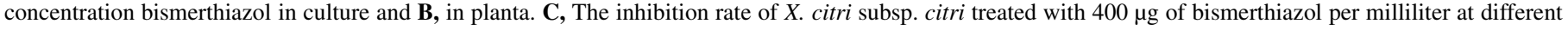

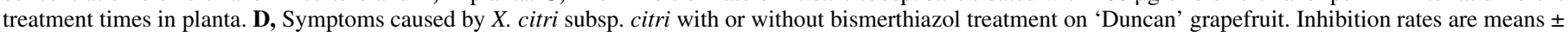

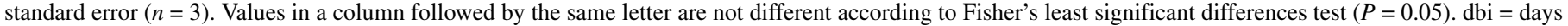
before inoculation; dpi = days postinoculation. 

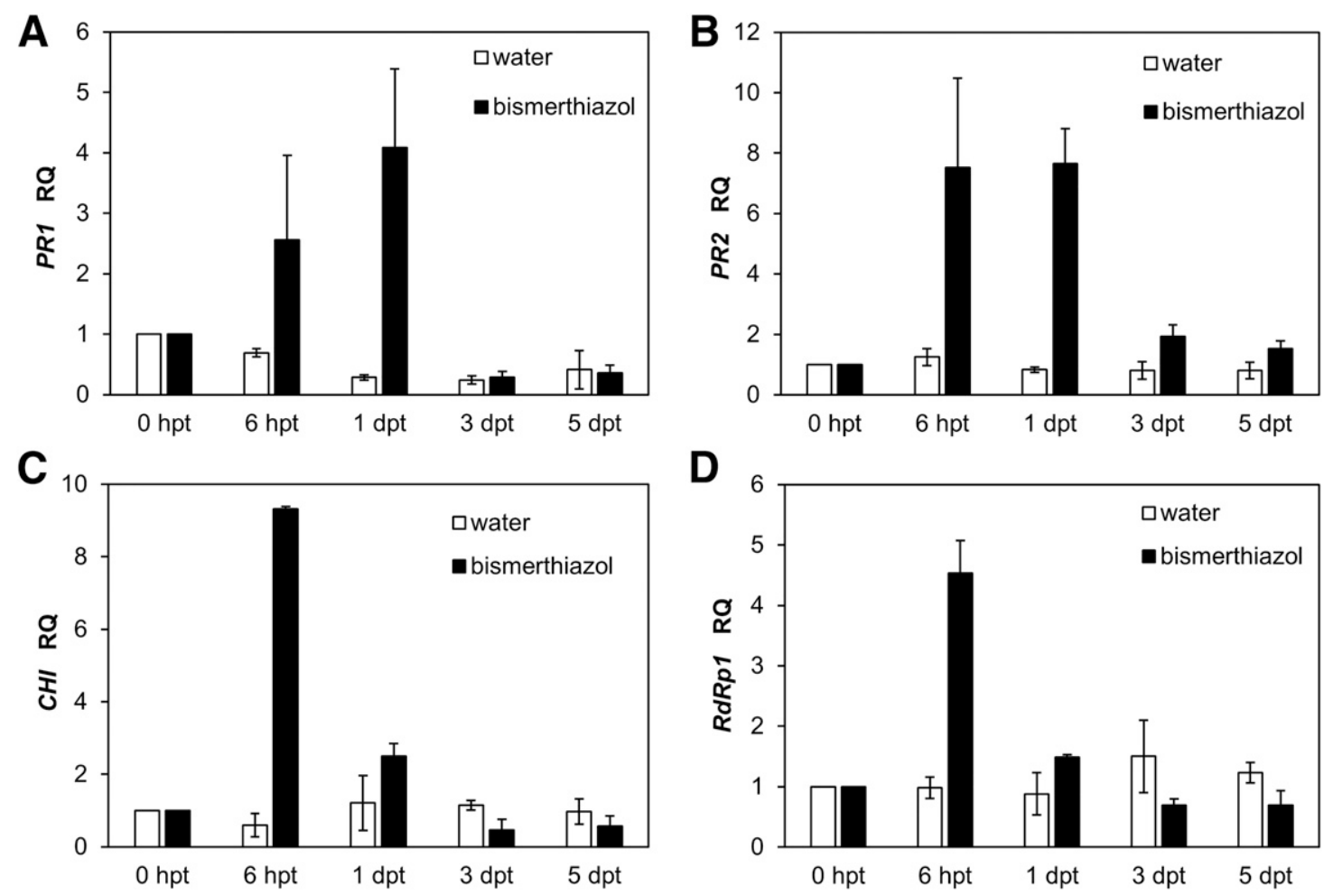

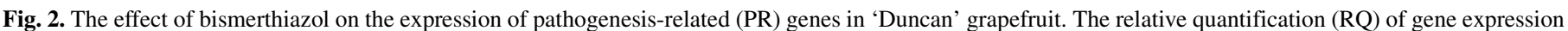

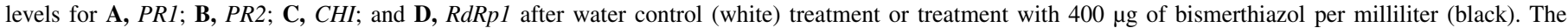

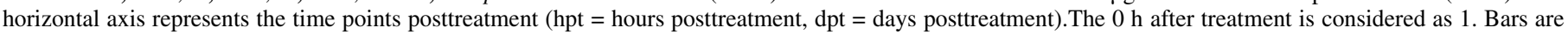
mean \pm standard error $(n=3)$.
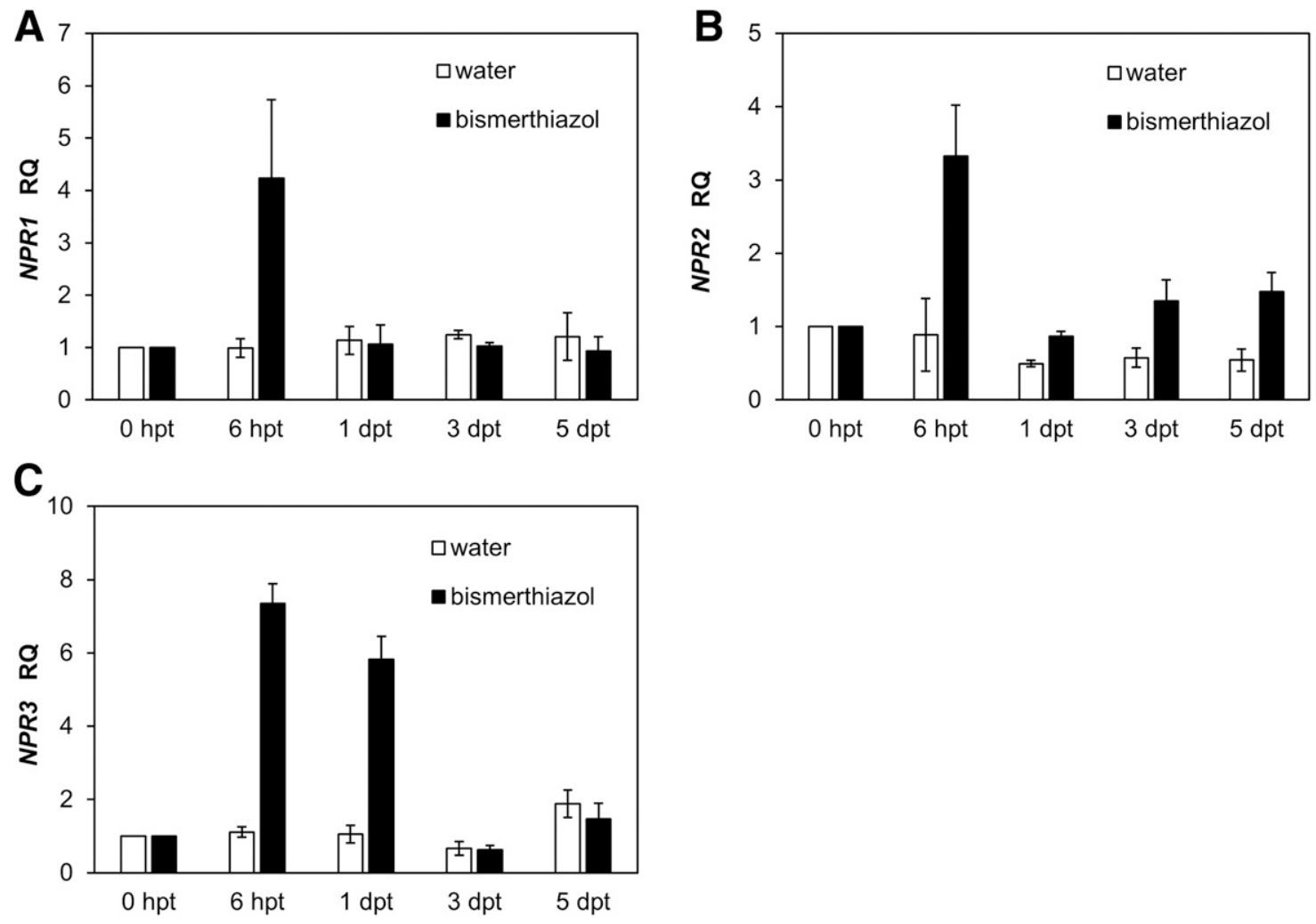

Fig. 3. The effect of bismerthiazol on the expression of nonexpresser of pathogenesis-related (NPR) genes in 'Duncan' grapefruit. The relative quantification (RQ) of gene expression levels for A, NPR1; $\mathbf{B}, N P R 2$; and $\mathbf{C}, N P R 3$ after water control (white) treatment or treatment with $400 \mu \mathrm{g}$ of bismerthiazol per milliliter (black). The horizontal axis represents the time point posttreatment $(\mathrm{hpt}=$ hours posttreatment, $\mathrm{dpt}=$ days posttreatment). The $0 \mathrm{~h}$ after treatment is considered as 1 . Bars are mean \pm standard error $(n=3)$. 
background levels by $1 \mathrm{dpt}$ (Fig. 3A and B), whereas NPR3 gene expression increased approximately sevenfold and remained elevated until 1 day after bismerthiazol treatment (Fig. 3C). Overall, bismerthiazol induced expression of both the $P R$ genes and the NPR genes in 'Duncan' grapefruit, with the increased expression seen mainly in the first day posttreatment.

Effects of bismerthiazol on the SA signaling pathway and the priming defense response in citrus. Many studies have reported that expression of the NPR genes is triggered by the accumulation of SA in a variety of plants (Dong 2004). To investigate if SA biosynthesis is regulated postbismerthiazol treatment, we measured the expression of two marker genes involved in SA biosynthesis, i.e., PALI (phenylalanine ammonia lyase 1) and ICS1 (isochorismate synthase 1). The expression of ICS1 was not up-regulated after bismerthiazol treatment, but $P A L 1$ expression was two- to fourfold higher at 3 and $5 \mathrm{dpt}$ (Fig. 4A and B). However, these results are in contrast to the expression of the NPR genes, since the NPR genes were mainly up-regulated at early treatment times, while the SA biosynthesis genes were triggered at later treatment time points. Although the expression of the NPR genes was not consistent with the molecular marker genes $P A L I$ and $I C S 1$, indicative of SA regulation in citrus, it is possible that bismerthiazol triggers the transcription of other genes that indirectly influence the SA signaling pathway.

It is also possible that PAL1 may be involved in the metabolism of other defense-related molecules. Notably, the final product of the PAL pathway, trans-cinnamic acid, is not only a substrate in the SA biosynthesis pathway but is also involved in the flavonoid biosynthesis pathway. Flavonoids are known to play a role in plant defense, and we were able to detect the expression of two marker genes in the flavonoid pathway in 'Duncan' grapefruit: CitCHS, encoding chalcone synthase, and $\mathrm{CitCHI}$, encoding chalcone isomerase. Our data showed that the expression level of CitCHS increased up to 10 -fold at $6 \mathrm{~h}$ and 1 day after treatment but was restored to background levels by $3 \mathrm{dpt}$, while the expression of CitCHI was up-regulated 2.5-fold during this same period (Fig. 4C and D). Thus, we assumed that the bismerthiazol treatment caused the induction of $\mathrm{CitCHS}$ and $\mathrm{CitCHI}$ in the flavonoid pathway in 'Duncan' grapefruit, which may indirectly influence the SA biosynthesis pathway and could, in turn, affect a series of genes (like the NPR and $P R$ genes) in the SA-dependent signaling defense pathway.

The gene encoding azelaic acid-induced 1 (AZII) is induced by azelaic acid, which confers local and systemic immunity to pathogen infection in plants and primes the plant to accumulate higher SA levels when challenged than nonprimed plants (Jung et al. 2009). Our data showed that the expression of AZII was increased approximately sixfold at $6 \mathrm{hpt}$ and gradually decreased to levels similar to that of the control by $3 \mathrm{dpt}$ (Fig. 4E). From this, we hypothesize that bismerthiazol triggers the priming defense of the plant, enhancing its resistance to various biotic or abiotic stresses.

Bismerthiazol had no effect on the jasmonate (JA) and auxin signaling pathways. JA and auxin are well-known signaling molecules that induce the defense response against many biotic and abiotic stresses in plants (Horváth et al. 2007). Two important genes in the JA signaling pathway include COII (coronatine-insensitive 1) and JARl (JA-resistant 1), which encode for an enzyme important for the activation of JA signaling and a JA receptor, respectively
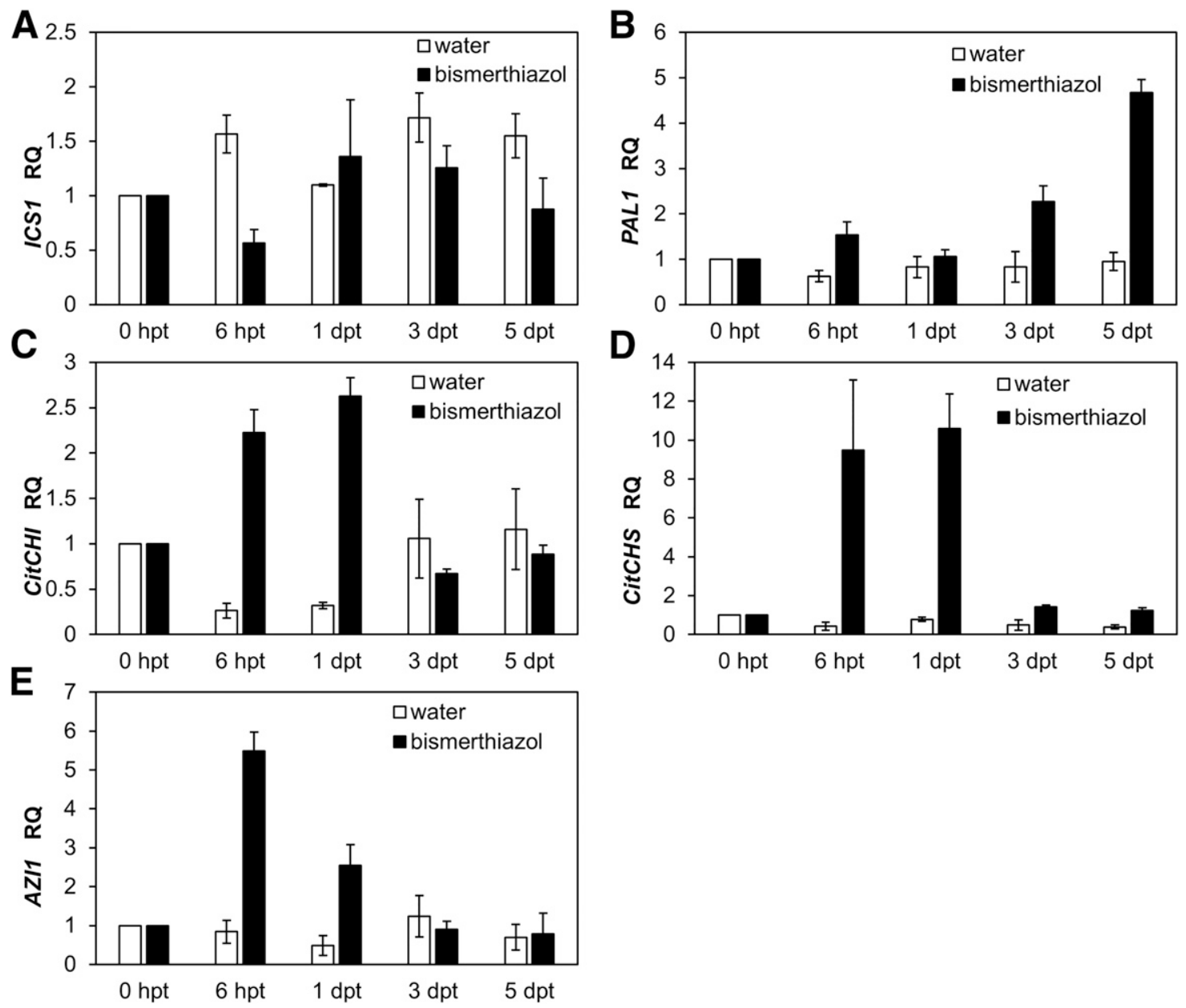

Fig. 4. The effect of bismerthiazol on the expression of salicylic acid signaling pathway-related genes in 'Duncan' grapefruit. The relative quantification (RQ) of gene expression levels for A, ICSI; B, PALI; C, CitCHI; D, CitCHS; and $\mathbf{E}$, AZI1 after water control (white) treatment or treatment with $400 \mu \mathrm{g}$ of bismerthiazol per milliliter (black). The horizontal axis represents the time point posttreatment (hpt $=$ hours posttreatment, $\mathrm{dpt}=$ days posttreatment). The $0 \mathrm{~h}$ after treatment is considered as 1 . Bars are mean \pm standard error $(n=3)$. 
(Staswick and Tiryaki 2004; Xie et al. 1998). In this study, the expression of COII and JARI showed no obvious upregulation after bismerthiazol treatment, as compared with the water-treated samples (Fig. 5A and B), which suggested that bismerthiazol had no effect on the JA-dependent defense response.

Auxin can induce the expression of the auxin/indole-3-acetic acid (Aux/IAA) protein family, which regulates plant growth and development (Wang et al. 2005). Under a high level of auxin, the IAA protein and an auxin receptor known as transport inhibitor response 1 (TIR1) can interact with each other to regulate plant growth and development (Rodrigues et al. 2013). Here, we measured the expression of marker genes IAA9 and TIRI in bismerthiazoltreated plants. Although the expression of IAA9 increased three- to fourfold throughout the entire time period following treatment, this increase also occurred in control samples and, thus, no significant difference in gene expression was found between the treated and nontreated plants (Fig. 4C). In addition, the expression of TIRl was not significantly different between the treated and nontreated plants (Fig. 4D). Taken together, the data suggests that the auxin signaling pathway was not triggered with bismerthiazol and that the increase in IAA9 seen in both the water control and the treated samples may have resulted from our use of young leaves for gene expression, since young tissues are in a natural state of development and expansion, which has been associated with IAA production (Ljung et al. 2001; PerrotRechenmann and Hagen 2002).

\section{DISCUSSION}

Bismerthiazol has been widely used to control $X$. oryzae pv. oryzae and $X$. oryzae pv. oryzicola infections in China. A previous study determined the $\mathrm{EC}_{50}$ of bismerthiazol for $X$. oryzae pv. oryzae in culture was $\sim 12 \mu \mathrm{g} / \mathrm{ml}$ and $\sim 18 \mu \mathrm{g} / \mathrm{ml}$ for $X$. oryzae pv. oryzicola (Liang et al. 2015a). In this paper, we demonstrate that bismerthiazol can also inhibit the growth of $X$. citri subsp. citri in culture and that the half maximal effective concentration $\left(\mathrm{EC}_{50}\right)$ of bismerthiazol on $X$. citri subsp. citri is $85 \mu \mathrm{g} / \mathrm{ml}$ in NB medium, which is greater than the concentration for $X$. oryzae $\mathrm{pv}$. oryzae and $X$. oryzae $\mathrm{pv}$. oryzicola. In agreement with the increased $\mathrm{EC}_{50}$ value for bismerthiazol on $X$. citri subsp. citri in culture, $X$. citri subsp. citri also has a higher tolerance to bismerthiazol in planta. 'Duncan' grapefruit needed concentrations of bismerthiazol $\geq 300 \mu \mathrm{g} / \mathrm{ml}$ in order to reduce the pathogen level by $\geq 90 \%$ compared with nontreated samples, while the lesion length from $X$. oryzae pv. oryzae in rice is reduced by $98 \%$ after treatment with bismerthiazol at $150 \mu \mathrm{g} / \mathrm{ml}$ (Liang et al. 2015a; Zhu et al. 2013). The timing of the treatment is also an important factor that influences the effectiveness of bismerthiazol on citrus canker, since the protective activity of bismerthiazol was found to be better than the curative activity on citrus canker, which is in agreement with the studies on $X$. oryzae $\mathrm{pv}$. oryzae and $X$. oryzae $\mathrm{pv}$. oryzicola (Zhu et al. 2013).

The main chemical control methods for citrus canker are copperbased bactericides, such as copper oxychloride, copper hydroxide, copper oxide, and basic copper sulfate. These kinds of bactericides are used to reduce the pathogen load on new leaf flushes and fruit surfaces. Research showed the use of $1,800 \mu \mathrm{g}$ of copper oxychloride per milliliter significantly decreased the incidence of citrus canker on leaves and harvested fruits, reduced the number of prematurely dropped fruits, and increased yields in various species of citrus trees (Behlau et al. 2010). Research also showed that 500 to $1,000 \mathrm{ppm}$ of streptomycin sulfate was effective when sprayed with $1 \%$ glycerine on acid lime (Rangaswami et al. 1959). Six sprays of $1,000 \mathrm{ppm}$ of streptomycin sulfate along with two prunings reduced the level of canker in acid lime (Balaraman and Purushotman, 1981). Here, bismerthiazol was shown to be effective at a much lower concentration (with a bismerthiazol concentration of 200 $\mu \mathrm{g} / \mathrm{ml}$ inhibiting the growth of $X$. citri subsp. citri by $50 \%$ percent) and that its effectiveness was greatest when plants were treated
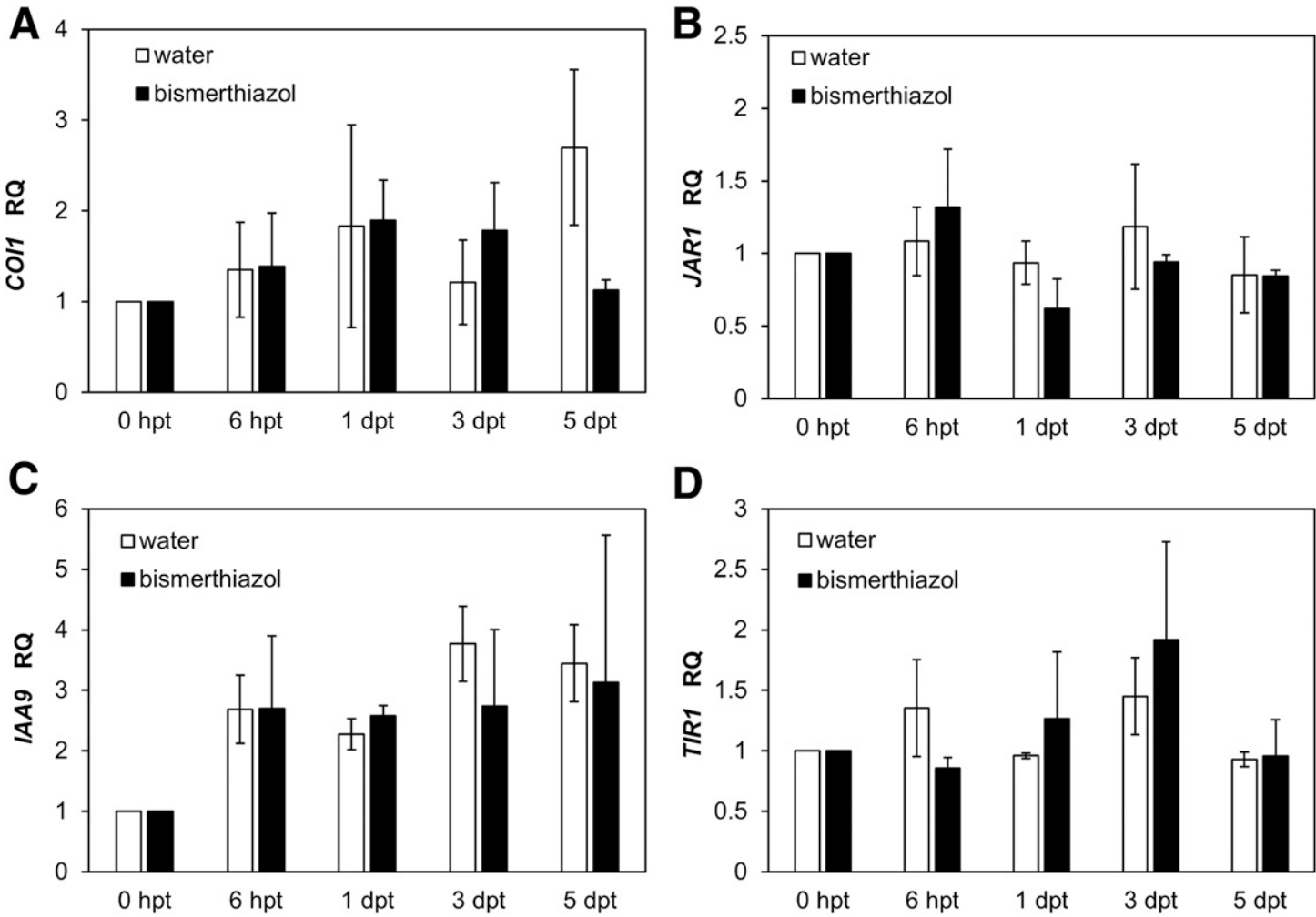

D

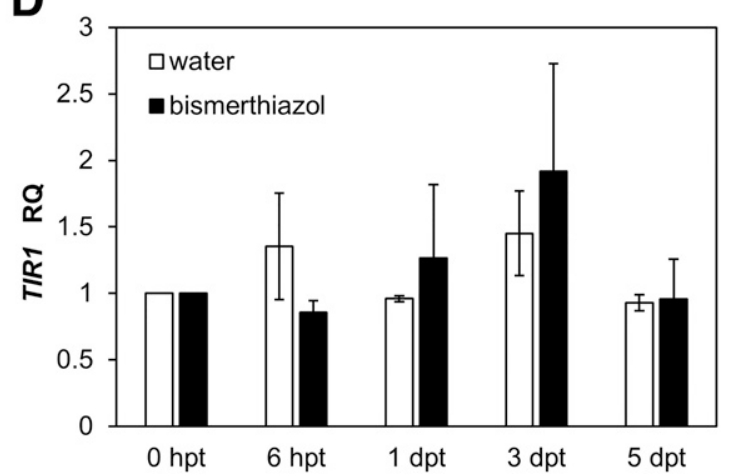

Fig. 5. The effect of bismerthiazol on the expression of jasmonate and auxin signaling pathway-related genes in 'Duncan' grapefruit. The relative quantification (RQ) of gene expression levels for A, COII; B, JARI; C, IAA9; and D, TIR1 after water control (white) treatment or greatment with $400 \mu \mathrm{g}$ of bismerthiazol per milliliter (black). The horizontal axis represents the time point posttreatment (hpt $=$ hours posttreatment, dpt $=$ days posttreatment). The $0 \mathrm{~h}$ after treatment is considered as 1 . Bars are mean \pm standard error $(n=3)$. 
prior to pathogen infection. With the widespread and frequent use of bismerthiazol to control the blight of rice, bismerthiazolresistant $X$. oryzae pv. oryzae have been selected for in many ricegrowing areas (Zhu et al. 2013). Because of this, when promoting bismerthiazol to control citrus canker, specified application times and concentrations for bismerthiazol should be adhered to and treatment regimens should include a rotation of effective chemicals in an effort to avoid the emergence of resistant strains.

In addition, we showed that bismerthiazol could induce the defense response in citrus during the first 24 hpt by detecting an increase in the expression of four $P R$ genes. PR proteins are induced under specific pathological conditions and are not pathogenspecific but are determined by the type of plant reaction (van Loon 1985). Some of these proteins are antimicrobial in nature, attacking molecules in the cell wall of a bacterium or fungus, while others work as signals that spread the "news" of an infection to nearby cells (Campbell and Reece 2005). Overall, the activation of PR proteins defines the occurrence of a defense response in plants. In a previous study, BTH and two fungicides (azoxystrobin and fenpropimorph) induced defense-associated gene expression in wheat, showing that $P R$ genes of wheat were up-regulated at early treatment times (Pasquer et al. 2005). An analysis of gene expression from cocoa during the early response to BTH showed 68 genes were up-regulated, including $P R$ genes (Verica et al. 2004). A comparable gene expression analysis of BTH-treated and untreated coffee leaves resulted in the identification of 71 genes differentially regulated in the coffee leaves $16 \mathrm{~h}$ after BTH treatment, which included a systemic increase in PR proteins (Bell et al. 2006). In general, the induction of the $P R$ genes in the present study is consistent with these studies regarding the timing of gene induction post-chemical treatment.

Chitinases are generally found in organisms that dissolve and digest the chitin of fungi and can be induced by chemical elicitors or by pathogen infection. Chitinases alone or in combination with glucanases can trigger a defensive response to fungal infection (van Loon et al. 2006). The $P R 2$ gene encoding $\beta-1,3$-glucanase is localized in plants and has been characterized in a wide range of species. It is important for cell division, regulation of callose turnover at the plasmodesmata, and withstanding abiotic stresses. In this study, the gene encoding $\beta$-1,3-glucanase was highly expressed, while the chitinase was up-regulated at $6 \mathrm{hpt}$, which infers that bismerthiazol triggers a combination of glucanase and chitinase activities to protect against pathogen infection.

In Arabidopsis, an NPRl gene mutant failed to express $P R$ genes after systemic acquired resistance is induced. A recent study also found that the NPR1 protein paralogues NPR3 and NPR4 act as SA receptors and modulate the interaction between SA and NPR1 (Fu et al. 2012). NPR3 and NPR4 proteins bind SA with different affinities, with NPR3 having a lower affinity for SA (micromolar range) than NPR4 (nanomolar range), which means that the NPR4 protein can bind SA at lower concentrations of SA in Arabidopsis (Moreau et al. 2012). NPR3 and NPR4 interact with TGA2 and its paralogs to negatively regulate the defense response and mediate degradation of NPR1 in Arabidopsis (Zhang et al. 2006). The citrus $N P R 2$ and NPR3 genes are homologous to Arabidopsis NPR3 and $N P R 4$ and may function similar to that reported in Arabidopsis (Shi et al. 2015). In this study, the expression of $N P R 1, N P R 2$, and NPR3 genes are all up-regulated $6 \mathrm{~h}$ after bismerthiazol treatment. It is possible that citrus also has several transcription factors that function like TGA2 and its paralogs in Arabidopsis and that they influence the interaction between NPR1, NPR2, and NPR3 and affect the defense response. But how the transcription factors in citrus regulate the interaction between NPR1, NPR2, and NPR3 is still not clear.

$N P R$ genes are usually induced by the accumulation of SA and, thus, follow the SA signaling pathway gene expression pattern. In general, plants have two distinct pathways for SA biosynthesis, one involving isochorismate synthase and the other involving PAL
(Mauch-Mani and Slusarenko 1996; Wildermuth et al. 2001). Although we failed to detect the regulation of ICS1 and PALI expression at the early treatment times, expression of the key enzymes and regulating factors of the flavonoid pathway (CitCHS and $(\mathrm{Cit} C H I$ ) were highly induced and are known to share the same substrates as the SA biosynthesis pathway. The analysis of $C H S$ and $\mathrm{CHI}$ transcripts has been used as a measure of the induced defense response in many studies (Dhawale et al. 1989; Habereder et al. 1989; Sallaud et al. 1997). CHS and CHI expression causes accumulation of flavonoid and is involved in the SA defense pathway (Dao et al. 2011). Induction of the CHS gene in SA-treated safflower was detected at early treatment times and was followed by the induction of the $P A L$ gene at the later treatment times (Dehghan et al. 2014), which is consistent with our results for the CitCHS and PAL expression patterns. Overall, bismerthiazol may be inducing the defense response in citrus by increasing the utilization of a substrate of PAL in the flavonoid pathway, which may be indirectly influencing SA biosynthesis and modulating the SA-dependent signaling pathway.

Priming is a unique physiological state in which cells respond to an extremely low level of a stimulus in a more rapid and robust manner. Primed plants have been shown to have a faster and stronger activation of the defense response when subsequently infected by pathogens (Conrath 2011). Priming has been shown to be induced by both natural and synthetic compounds, such as SA and BTH (Conrath et al. 2006). The high expression of the priming-associated gene AZII in this study suggests that the bismerthiazol-inducible defense likely involves the priming defense response in plants.

JA is a well-known signaling molecule that induces the defense response to many biotic and abiotic stresses in various plants (Horváth et al. 2007). The accumulation of JA increases when host plants are infected by a pathogen or have tissue damage, and the application of JA can induce defense-associated gene expression (Wasternack 2007). We failed to detect any significant transcriptional modulation of the marker genes in the JA signaling pathway, which is consistent with the theory that SA and JA defense pathways are mutually antagonistic (Bari and Jones 2009). Another important hormone, auxin, which controls plant growth and developmental processes, also acts as a signaling molecule in response to pathogen infection and environmental stress (Bari and Jones 2009). We found that the expression of IAA9 is up-regulated in both treated and nontreated samples while the expression of TIRI was not affected. These results indicate that the auxin signaling pathway was not involved in the bismerthiazol-induced defense response and can be explained by the fact that the samples collected for gene expression were very young tissues, which would be synthesizing auxin for cell division, extension, and differentiation (Leyser 2006). Taken together, the lack of expression of marker genes in the JA and auxin signaling pathways revealed that the bismerthiazol-induced defense response does not involve these hormones signaling networks.

In conclusion, this study demonstrated that bismerthiazol effectively inhibited the growth of $X$. citri subsp. citri in medium and in citrus and induced a defense response at the early treatment times in 'Duncan' grapefruit plants, even without pathogen infection. The mode of action of this inducible resistance may involve the SA signaling pathway and triggering of the priming defense in plants, which explains why the defense response is stronger after pathogen infection in the bismerthiazol-treated plants than in nontreated plants.

\section{ACKNOWLEDGMENTS}

We would like to thank C. Latza and Y. Cui for their excellent technical assistance. Funding was provided by the United States Department of Agriculture. Mention of trade names or commercial products in this article is solely for the purpose of providing specific information and does not imply recommendation or endorsement by the U.S. Department of Agriculture. 


\section{LITERATURE CITED}

Ahn, I.-P., Kim, S., Lee, Y.-H., and Suh, S. C. 2007. Vitamin B1-induced priming is dependent on hydrogen peroxide and the NPRl gene in Arabidopsis. Plant Physiol. 143:838-848.

Alva, A. K., Graham, J. H., and Anderson, C. A. 1995. Soil pH and copper effects on young 'Hamlin' orange trees. Soil Sci. Soc. Am. J. 59:481-487.

Bajpai, V. K., Cho, M. J., and Kang, S. C. 2010. Control of plant pathogenic bacteria of Xanthomonas spp. by the essential oil and extracts of Metasequoia glyptostroboides Miki ex Hu in vitro and in vivo. J. Phytopathol. 158:479-486.

Balaraman, K., and Purushotman, R. 1981. Control of citrus canker on acid lime. South Indian Hortic. 29:175-177.

Bari, R., and Jones, J. D. 2009. Role of plant hormones in plant defence responses. Plant Mol. Biol. 69:473-488.

Beaudoin, A. R. 1973. Teratogenic activity of 2-amino-1, 3, 4-thiadiazole hydrochloride in Wistar rats and the protection afforded by nicotinamide. Teratology 7:65-71.

Behlau, F., Belasque, J., Graham, J., and Leite, R. 2010. Effect of frequency of copper applications on control of citrus canker and the yield of young bearing sweet orange trees. Crop Prot. 29:300-305.

Bell, J., De Nardi, B., Dreos, R., Del Terra, L., Martellossi, C., Asquini, E., Tornincasa, P., Gasperini, D., Pacchioni, B., and Rathinavelu, R. 2006. Differential responses of Coffea arabica L. leaves and roots to chemically induced systemic acquired resistance. Genome 49:1594-1605.

Burketová, L., Šindelářová, M., and Šindelář, L. 1999. Benzothiadiazole as an inducer of $\beta$-1, 3-glucanase and chitinase isozymes in sugar beet. Biol. Plant. 42:279-287.

Campbell, N., and Reece, J. 2005. Biology, 7th Edition. Benjamin Cummings Publishing Company, Inc., San Francisco.

Cao, H., Bowling, S. A., Gordon, A. S., and Dong, X. 1994. Characterization of an Arabidopsis mutant that is nonresponsive to inducers of systemic acquired resistance. Plant Cell 6:1583-1592.

Conrath, U. 2011. Molecular aspects of defence priming. Trends Plant Sci. 16: 524-531.

Conrath, U., Beckers, G. J., Flors, V., García-Agustín, P., Jakab, G., Mauch, F., Newman, M.-A., Pieterse, C. M., Poinssot, B., and Pozo, M. J. 2006. Priming: Getting ready for battle. Mol. Plant Microbe Interact. 19:10621071.

Conrath, U., Pieterse, C. M., and Mauch-Mani, B. 2002. Priming in plantpathogen interactions. Trends Plant Sci. 7:210-216.

Dao, T., Linthorst, H., and Verpoorte, R. 2011. Chalcone synthase and its functions in plant resistance. Phytochem. Rev. 10:397-412.

Dehghan, S., Sadeghi, M., Poppel, A., Fischer, R., Lakes-Harlan, R., Kavousi, H. R., Vilcinskas, A., and Rahnamaeian, M. 2014. Differential inductions of phenylalanine ammonia-lyase and chalcone synthase during wounding, salicylic acid treatment, and salinity stress in safflower, Carthamus tinctorius. Biosci. Rep. 34:273-282.

Dhawale, S., Souciet, G., and Kuhn, D. N. 1989. Increase of chalcone synthase mRNA in pathogen-inoculated soybeans with race-specific resistance is different in leaves and roots. Plant Physiol. 91:911-916.

Dong, X. 2004. NPR1, all things considered. Curr. Opin. Plant Biol. 7:547552.

Dufour, M., Lambert, C., Bouscaut, J., Mérillon, J., and Corio-Costet, M. 2013. Benzothiadiazole-primed defence responses and enhanced differential expression of defence genes in Vitis vinifera infected with biotrophic pathogens Erysiphe necator and Plasmopara viticola. Plant Pathol. 62: 370-382.

Durrant, W., and Dong, X. 2004. Systemic acquired resistance. Annu. Rev. Phytopathol. 42:185-209.

Francis, M. I., Redondo, A., Burns, J. K., and Graham, J. H. 2009. Soil application of imidacloprid and related SAR-inducing compounds produces effective and persistent control of citrus canker. Eur. J. Plant Pathol. 124: 283-292.

Friedrich, L., Lawton, K., Ruess, W., Masner, P., Specker, N., Rella, M. G., Meier, B., Dincher, S., Staub, T., and Uknes, S. 1996. A benzothiadiazole derivative induces systemic acquired resistance in tobacco. Plant J. 10: 61-70.

Fu, Z. Q., Yan, S., Saleh, A., Wang, W., Ruble, J., Oka, N., Mohan, R., Spoel, S. H., Tada, Y., and Zheng, N. 2012. NPR3 and NPR4 are receptors for the immune signal salicylic acid in plants. Nature 486:228-232.

Gottwald, T. R., Graham, J. H., and Schubert, T. S. 2002. Citrus canker: The pathogen and its impact. Plant Health Prog. 10.

Graham, J. H., Gottwald, T. R., Cubero, J., and Achor, D. S. 2004. Xanthomonas axonopodis pv. citri: Factors affecting successful eradication of citrus canker. Mol. Plant Pathol. 5:1-15.

Graham, J. H., and Myers, M. E. 2011. Soil application of SAR inducers imidacloprid, thiamethoxam, and acibenzolar-S-methyl for citrus canker control in young grapefruit trees. Plant Dis. 95:725-728.
Habereder, H., Schröder, G., and Ebel, J. 1989. Rapid induction of phenylalanine ammonia-lyase and chalcone synthase mRNAs during fungus infection of soybean (Glycine max L.) roots or elicitor treatment of soybean cell cultures at the onset of phytoalexin synthesis. Planta 177:58-65.

Harel, Y. M., Mehari, Z. H., Rav-David, D., and Elad, Y. 2014. Systemic resistance to gray mold induced in tomato by benzothiadiazole and Trichoderma harzianum T39. Phytopathology 104:150-157.

Horváth, E., Szalai, G., and Janda, T. 2007. Induction of abiotic stress tolerance by salicylic acid signaling. J. Plant Growth Regul. 26:290-300.

Jung, H. W., Tschaplinski, T. J., Wang, L., Glazebrook, J., and Greenberg, J. T. 2009. Priming in systemic plant immunity. Science 324:89-91.

Kohler, A., Schwindling, S., and Conrath, U. 2002. Benzothiadiazole-induced priming for potentiated responses to pathogen infection, wounding, and infiltration of water into leaves requires the NPR1/NIM1 gene in Arabidopsis. Plant Physiol. 128:1046-1056.

Lawton, K. A., Friedrich, L., Hunt, M., Weymann, K., Delaney, T., Kessmann, H., Staub, T., and Ryals, J. 1996. Benzothiadiazole induces disease resistance in Arabidopsis by activation of the systemic acquired resistance signal transduction pathway. Plant J. 10:71-82.

Leyser, O. 2006. Dynamic integration of auxin transport and signaling. Curr. Biol. 16:R424-R433.

Liang, X., Duan, Y., Yu, X., Wang, J., and Zhou, M. 2015a. Photochemical degradation of bismerthiazol: Structural characterisation of the photoproducts and their inhibitory activities against Xanthomonas oryzae pv. oryzae. Pest Manag. Sci. 72:997-1003.

Liang, X., Yu, X., Dong, W., Guo, S., Xu, S., Wang, J., and Zhou, M. 2015b. Two thiadiazole compounds promote rice defence against Xanthomonas oryzae pv. oryzae by suppressing the bacterium's production of extracellular polysaccharides. Mol. Plant Pathol. 16:882-92.

Ljung, K., Bhalerao, R., and Sandberg, G. 2001. Site and homeostatic control of auxin biosynthesis in Arabidopsis during vegetative growth. Plant J. 28: 465-474.

Mauch, F., Mauch-Mani, B., and Boller, T. 1988. Antifungal hydrolases in pea tissue II. Inhibition of fungal growth by combinations of chitinase and $\beta-1$, 3-glucanase. Plant Physiol. 88:936-942.

Mauch-Mani, B., and Slusarenko, A. J. 1996. Production of salicylic acid precursors is a major function of phenylalanine ammonia-lyase in the resistance of Arabidopsis to Peronospora parasitica. Plant Cell 8:203-212.

Mavrodieva, V., Levy, L., and Gabriel, D. W. 2004. Improved sampling methods for real-time polymerase chain reaction diagnosis of citrus canker from field samples. Phytopathology 94:61-68.

McCollum, G., Stange, R., Albrecht, U., Bowman, K., Niedz, R., and Stover, E. 2011. Development of a qPCR technique to screen for resistance to Asiatic citrus canker. Acta Hortic. 892:173-181.

Moreau, M., Tian, M., and Klessig, D. F. 2012. Salicylic acid binds NPR3 and NPR4 to regulate NPR1-dependent defense responses. Cell Res. 22:16311633.

Paranjape, K., Gowariker, V., Krishnamurthy, V. N., and Gowariker, S. 2014. The Pesticide Encyclopedia. CABI Publishing, Wallingford, U.K.

Pasquer, F., Isidore, E., Zarn, J., and Keller, B. 2005. Specific patterns of changes in wheat gene expression after treatment with three antifungal compounds. Plant Mol. Biol. 57:693-707.

Perrot-Rechenmann, C., and Hagen, G., eds. 2002. Auxin molecular biology. Page 18. Kluwer Academic Publishers, Dorcrecht, The Netherlands.

Pitino, M., Armstrong, C. M., and Duan, Y. 2015. Rapid screening for citrus canker resistance employing pathogen-associated molecular patterntriggered immunity responses. Hortic. Res. 2:15042.

Rangaswami, G., Rao, R. R., and Lakshmanan, A. R. 1959. Studies on the control of citrus canker with Streptomycin. Phytopathology 49:224-226.

Rodrigues, C. M., de Souza, A. A., Takita, M. A., Kishi, L. T., and Machado, M. A. 2013. RNA-Seq analysis of Citrus reticulata in the early stages of Xylella fastidiosa infection reveals auxin-related genes as a defense response. BMC Genomics 14:676.

Ryals, J. A., Neuenschwander, U. H., Willits, M. G., Molina, A., Steiner, H.-Y., and Hunt, M. D. 1996. Systemic acquired resistance. Plant Cell 8:1809.

Sallaud, C., Zuanazzi, J., El-Turk, J., Leymarie, J., Breda, C., Buffard, D., de Kozak, I., Ratet, P., Husson, P., and Kondorosi, A. 1997. Gene expression is not systemically linked to phytoalexin production during alfalfa leaf interaction with pathogenic bacteria. Mol. Plant Microbe Interact. 10:257-267.

Shen, G. B., and Zhou, M. G. 2001. Action mode of bismerthiazol against rice leaf blight. Chin. J. Pesticides 3:35-39.

Shi, Q., Febres, V. J., Jones, J. B., and Moore, G. A. 2015. Responsiveness of different citrus genotypes to the Xanthomonas citri ssp. citri-derived pathogen-associated molecular pattern (PAMP) flg22 correlates with resistance to citrus canker. Mol. Plant Pathol. 16:507-520.

Stall, R. E., Miller, J. W., Marcó, G. M., and de Echenique, B. C. 1981. Population dynamics of Xanthomonas citri causing cancrosis of citrus in Argentina. Pages 10-14 in: Proceedings of the Florida State Horticultural Society, Vol. 93. CABI Publishing, Wallingford, U.K. 
Staswick, P. E., and Tiryaki, I. 2004. The oxylipin signal jasmonic acid is activated by an enzyme that conjugates it to isoleucine in Arabidopsis. Plant Cell 16:2117-2127.

Stover, E., and McCollum, T. 2011. Levels of Candidatus Liberibacter asiaticus and Xanthomonas citri in diverse citrus genotypes and relevance to potential transmission from pollinations. HortScience 46:854-857.

Sun, H. M., Li, B. T., Guo, M. C., Che, C. X., Xie, J. Z., and Liu, D. L. 2011. Bioactivity of Several bactericides against Xanthomonas campestris pv. citri. Acta Agric. Univ. Jiangxiensis 33:38-42.

van Loon, L. 1985. Pathogenesis-related proteins. Plant Mol. Biol. 4:111-116.

van Loon, L. C., Rep, M., and Pieterse, C. 2006. Significance of inducible defense-related proteins in infected plants. Annu. Rev. Phytopathol. 44: 135-162.

Verica, J. A., Maximova, S. N., Strem, M. D., Carlson, J. E., Bailey, B. A., and Guiltinan, M. J. 2004. Isolation of ESTs from cacao (Theobroma cacao L.) leaves treated with inducers of the defense response. Plant Cell Rep. 23: 404-413.

Wadhwani, T., Desai, K., Patel, D., Lawani, D., Bahaley, P., Joshi, P., and Kothari, V. 2009. Effect of various solvents on bacterial growth in context of determining MIC of various antimicrobials. Internet J. Microbiol. 7.

Wang, H., Jones, B., Li, Z., Frasse, P., Delalande, C., Regad, F., Chaabouni, S., Latche, A., Pech, J.-C., and Bouzayen, M. 2005. The tomato Aux/IAA transcription factor IAA9 is involved in fruit development and leaf morphogenesis. Plant Cell 17:2676-2692.
Ward, E. R., Uknes, S. J., Williams, S. C., Dincher, S. S., Wiederhold, D. L., Alexander, D. C., Ahl-Goy, P., Metraux, J., and Ryals, J. A. 1991. Coordinate gene activity in response to agents that induce systemic acquired resistance. Plant Cell 3:1085-1094.

Wasternack, C. 2007. Jasmonates: An update on biosynthesis, signal transduction and action in plant stress response, growth and development. Ann. Bot. (Lond.) 100:681-697.

Wildermuth, M. C., Dewdney, J., Wu, G., and Ausubel, F. M. 2001. Isochorismate synthase is required to synthesize salicylic acid for plant defence. Nature 414:562-565

Xie, D.-X., Feys, B. F., James, S., Nieto-Rostro, M., and Turner, J. G. 1998. COI1: An Arabidopsis gene required for jasmonate-regulated defense and fertility. Science 280:1091-1094.

Xie, Z., Fan, B., Chen, C., and Chen, Z. 2001. An important role of an inducible RNA-dependent RNA polymerase in plant antiviral defense. Proc. Natl. Acad. Sci. U.S.A. 98:6516-6521.

Zhang, Y., Cheng, Y. T., Qu, N., Zhao, Q., Bi, D., and Li, X. 2006. Negative regulation of defense responses in Arabidopsis by two NPR1 paralogs. Plant J. 48:647-656

Zhongyin, M. Z. Z. M. Y. 1997. The action mode of Saikuzuo against Xanthomonas oryzae pv. oryzae. Acta Phytopathologica Sin. 3.

Zhu, X.-F., Xu, Y., Peng, D., Zhang, Y., Huang, T.-T., Wang, J.-X., and Zhou, M.-G. 2013. Detection and characterization of bismerthiazol-resistance of Xanthomonas oryzae pv. oryzae. Crop Prot. 47:24-29. 